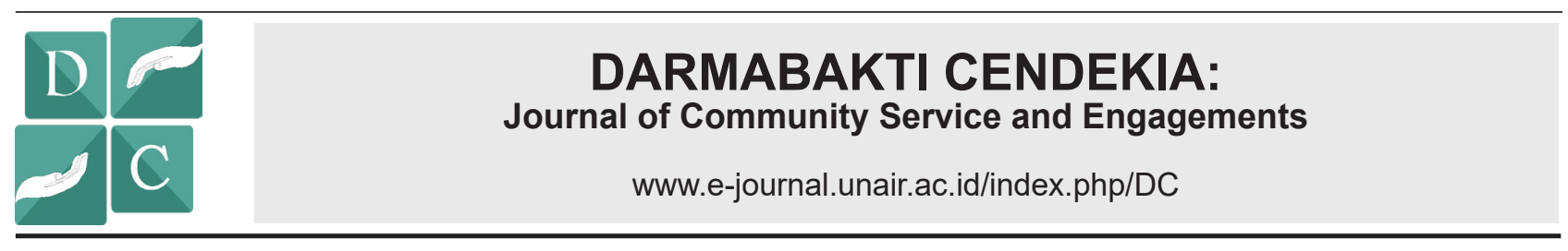

\section{GEMA CERMAT (GERAKAN MASYARAKAT CERDAS MENGGUNAKAN OBAT) FOR STUDENT IN THE CITY OF KENDARI SOUTHEAST SULAWESI}

\author{
GEMA CERMAT (GERAKAN MASYARAKAT CERDAS \\ MENGGUNAKAN OBAT) PADA PELAJAR DI KOTA KENDARI \\ SULAWESI TENGGARA
}

Scope:

Health

\author{
Suryani ${ }^{1}$ L. O. M. Fitrawan' ${ }^{1}$ Waode Sukmawati Arsyad ${ }^{2}$, Rina Andriani ${ }^{1}$, Rini Hamsidi ${ }^{*}$ \\ ${ }^{1}$ Faculty of Pharmacy, Halu Oleo University, Kendari-Indonesia \\ ${ }^{2}$ Faculty of Mathematics and Natural Sciences, Halu Oleo University, Kendari-Indonesia \\ ${ }^{3}$ Department of Health, Faculty of Vocational Studies, Universitas Airlangga, Surabaya-Indonesia
}

\begin{abstract}
A B S T R A C T
Background: The problem of rational use of drugs in the community, especially among students, still not many know or still lack of knowledge. The careful echo is a joint effort of the government and the community through a series of activities in realizing the awareness, awareness, understanding and community skills in using drugs appropriately and correctly. Purpose: This activity aims as an effort to improve understanding, knowledge and awareness of the community, especially students about the use of appropriate and correct medicines by providing training in the skills to choose and use drugs properly for self-medication so that drug abuse does not occur as a manifestation of the Program of Echoing Careful. Method: The method to be used in increasing knowledge was the Active Learning method (CBIA). This method was an educational model of community empowerment to be more skilled in choosing drugs so that self-medication becomes more effective, safe, and cost-effective. Results: The result of this program was an increase in student understanding of the types of drugs, forms of drug preparation, and independence in choosing, obtaining, using, storing, and destroying / disposing of drugs correctly and appropriately. Conclusion: The Schematic Echoes Program (GeMa CerMat) increased student knowledge about rational use of drugs and self-medication (Swamedikasi) through how to properly manage drugs, use and choose drugs correctly, and or how to see their efficacy and side effects.
\end{abstract}

\section{A B S T R A K}

Latar belakang: Masalah penggunaan obat yang rasional di masyarakat terutama pada kalangan pelajar masih belum banyak yang mengetahui atau masih minim pengetahuan. Oleh karena itu, pemerintah melalui program gerakan masyarakat cerdas menggunakan obat yang bekerjasama dengan masyarakat mengharapkan adanya peningkatan pengetahuan, pemahaman dan keterampilan dalam penggunaan obat yang baik dan bijak sehingga melahirkan kepedulian dan kesadaran dalam penggunaan obat yang beredar di masyarakat. Tujuan: Kegiatan ini bertujuan sebagai upaya peningkatan pengetahuan, pemahaman dan keterampilan dalam penggunaan obat yang baik dan bijak melalui praktek langsung untuk memilih obat-obatan yang benar agar dalam penggunaannya dapat terkontrol sesuai dengan program yang diberikan. Metode: Metode yang digunakan dalam pelaksanaan kegiatan ini yaitu pengembangan metode yang berbasis keaktifan siswa (CBIA) untuk meningkatkan pengetahuan dan keterampilan sehingga mampu memilih obat yang beredar di masyarakat secara bijak dan rasional. Hasil: Hasil dari program ini adalah adanya peningkatan pemahaman pelajar/siswa mengenai berbagai macam obat, bentuk sediaan obat, dan kemandirian dalam memilih, mendapatkan, menggunnakan, menyimpan, dan memusnakan/membuang obat dengan benar dan tepat. Kesimpulan: Kegiatan GeMa CerMat ini menambah pengetahuan peserta tentang penggunaan obat yang rasional dan pengobatan sendiri atau swamedikasi melalui bagaimana mengelola obat dengan baik, menggunakan dan memilih obat dengan benar, dan atau cara melihat khasiat dan efek sampingnya.

\author{
ARTICLE INFO \\ Recieved 29 Oktober 2019 \\ Accepted 20 November 2019 \\ Online 28 Juni 2020 \\ *Correspondence (Korespondensi): \\ Rini Hamsidi \\ E-mail: \\ rini.hamsidi@vokasi.unair.ac.id
}

Keywords:

Gema Cermat; Self-medication; Rational use of drugs

Kata kunci:

Gema Cermat; Swamedikasi; Penggunaan obat yang rasional 


\section{PENDAHULUAN}

Penggunaan obat yang tidak rasional di masyarakat masih sangat tinggi dilihat dari pembelian antibiotik secara bebas tanpa resep dokter, penggunaan obat bebas secara berlebih (over dosis), adanya efek samping, interaksi obat atau penyalahgunaan obat yang sering kali terjadi di masyarakat khususnya kalangan pelajar dimana banyak didapatkan anak-anak yang masih dibawah umur menyalahgunakan obat-obatan sehingga menyebabkan masalah baru dalam kesehatan. Rendahnya tingkat pemahaman di masyarakat mengenai cara penggunaan, penyimpanan dan membuang/memusnahkan obat dengan benar.

Obat dikatakan rasional apabila memenuhi tepat pasien, tepat indikasi, tepat obat, tepat dosis dan tepat cara dan lama penggunaan. Berdasarkan laporan yang diterima oleh World Helath Organization (WHO) masih tingginya penggunaan obat yang tidak rasional dimana terdapat lebih dari $50 \%$ dari seluruh penggunaan obat-obatan tidak tepat dalam peresepan, menyiapkan obat dan menjualnya, untuk $50 \%$ lainnya pasien tidak tepat dalam menggunakan obat. Adanya keterbatasan dalam mengakses obat esensial juga dialami oleh sepertiga dari jumlah penduduk di dunia. Angka kejadian ini dapat diatasi dengan pemberian resep yang sesuai dengan pedoman yang telah ditetapkan, penggunaan antimikroba yang tidak tepat, polifarmasi, penggunaan obat non-esensial, penggunaan injeksi secara berlebihan (Ihsan et al., 2017). Resistensi antibiotik merupakan akibat dari peresepan yang tidak rasional yang mengakibatkan penambahan biaya. Oleh karena itu dengan pengobatan yang rasional diharapkan dapat meningkatkan taraf hidup masyarakat yang baik dalam hal kualitas maupun kesejahteraan (Nining., 2019). Masyarakat yang sehat, sejahtera dan etos kerja yang tinggi dapat mempercepat pertumbuhan perekonomian dalam menjaga ketahanan bangsa dan negara.

Swamedikasi sering dilakukan oleh masyarakat. Dalam swamedikasi sebaiknya mengikuti persyaratan penggunaan obat rasional. Swamedikasi atau yang dikenal dengan pengobatan sendiri adalah suatu usaha dengan cara mengobati diri sendiri sesuai dengan kemampuan atau pengalaman yang dimiliki, untuk mengatasi penyakit-penyakit ringan antara lain, sakit kepala, pening, nyeri pada anggota tubuh, panas, maag, sakit perut (diare/sembelit), flu dan batuk serta penyakit kulit. Pengobatan sendiri ini dapat dilakukan dengan kerjasama dengan apoteker agar tidak terjadi kesalahan dalam pengobatan agar masyarakat dapat membeli obat-obat bebas dan obat bebas terbatas untuk mengatasi masalah kesehatan yang dialaminya.
Apoteker Penanggungjawab Apotek merupakan profesi kesehatan yang memiliki peran dalam menyediakan informasi yang berhubungan dengan obat obatan yang aman yang dapat diperjualbelikan tanpa resep dokter serta pemakaiannya tidak memiliki efek samping yang membahayakan masyarakat.

Minimnya pengetahuan masyarakat akan pengobatan rasional sehinga perlu adanya kerjasama antara pemerintah pusat, daerah dan masyarakat untuk mengadakan rangkaian kegiatan yang dapat menstimulus pengetahuan, kepedulian, kesadaran, pemahaman dan keterampilan akan penggunaan obat dengan baik dan bijak. (Kementerian Kesehatan Republik Indonesia, 2015). Tujuan dari pelaksanaan Gema Cermat untuk meningkatkan pemahaman dan kesadaran masyarakat akan pentingnya penggunaan obat secara baik, tepat dan benar. Selain itu juga untuk meningkatkan kemandirian masyarakat dalam memilih, mendapatkan, menggunakan, menyimpan, dan memusnahkan obat secara baik, tepat dan benar sehingga penggunaan obat secara rasional di masyarakat meningkat (Kementerian Kesehatan Republik Indonesia, 2015). Oleh karena itu, diperlukan campur tangan pemerintah dan masyarakat dalam program Gema Cermat sehingga hasilnya dapat dirasakan bagi setiap orang.

Pengembangan metode pengajaran yang berbasis pada keaktifan siswa yaitu Cara Belajar Insan Aktif atau Community Based Interactive Approach (CBIA) memberikan dampak langsung kepada peserta. Pemberian media dapat meningkatkan visual yang menggambarkan informasi yang dicari dan menumbuhkan motivasi peserta untuk belajar lebih terhadap informasi yang didapat sebelumnya (Lathifah et al., 2015; Rachmawati, 2016). Belajar mandiri merupakan suatu proses pemberian pengaruh secara langsung oleh fasilitator atau narasumber kepada peserta (Bela et al., 2016). Metode yang digunakan dalam pelaksanaan kegiatan ini yaitu pengembangan metode yang berbasis keaktifan siswa(CBIA) untuk meningkatkan pengetahuan dan keterampilan sehingga mampu memilih obat yang beredar di masyarakat secara bijak dan rasional. Melalui metode ini mampu menumbuhkan minat pelajar untuk belajar dan mempraktekkan dalam kegiatan yang disenangi (Lathifah et al., 2015; Rachmawati, 2016).

\section{METODE}

\section{Tempat Pelaksanaan}

Pengabdian masyarakat (Pengmas) ini dilaksanakan di SMPN 15 Kendari, Sulawesi 
Tenggara pada tanggal 16 September 2019. Kegiatan ini diikuti oleh 25 peserta yang merupakan siswa-siswi SMPN 15 Kendari yang diharapkan menjadi kader-kader muda yang dalam menerapkan swamedikasi dan penggunaan obat dengan cermat.

\section{Metode Pelaksanaan}

Metode kegiatan pengabdian ini adalah pengembangan metode pengajaran yang berbasis pada keaktifan siswa yaitu Cara Belajar Insan Aktif atau Community Based Interactive Approach (CBIA) dengan harapan dapat meningkatkan pengetahuan masyarakat dalam pemilihan obat secara rasional. Kegiatan pengabdian masyarakat dilakukan dengan 2 tahapan, yaitu:

1. Pemberian pretest berupa pengisian kuisioner untuk mengetahui tingkat pengetahuan sebelum penyuluhan dan posttest dengan menggunakan kuesioner yang sama kepada peserta untuk mengetahui pengaruh pemberian edukasi Gema Cermat terhadap tingkat pengetahuan peserta tentang swamedikasi agar kedepannya lebih bijak dalam memilih dan menggunakan obat bebas yang beredar di masyarakat.

2. Penyuluhan Gema Cermat dengan metode CBIA.

Dalam pelaksanaan kegiatan ini setiap peserta dikelompokan menjadi 7 kelompok sesuai dengan jumlah narasumber sebagai fasilitator. Fasilitator akan memberikan pengarahan mengenai Gema Cermat yang dibagi dalam 3 kegiatan utama. Paket obat yang terdiri dari berbagai jenis obat dibagikan kepada setiap kelompok yang berjumlah 10 orang. Setelah itu dilanjutkan dengan pengamatan dalam kelompok (Kegiatan pertama) : pengamatan yang dilakukan dengan melihat secara detail kemasan obat (merek obat, kandungan senyawa aktif, bahan penguat dan tambahan pada obat) Cara pengelompokan obat berdasarkan jenis bahan aktif bukan berdasarkan indikasi. Setelah itu dilakukan diskusi hasil pengamatan agar peserta memahami jenisjenis bahan aktif yang terkandung dalam suatu obat. Kegiatan kedua masih dalam kelompok dengan melakukan pengumpulan data yang menjadi acuan dalam mengobati diri sendiri, yaitu : urutan komponen bahan aktif dan tambahan, aturan pakai, khasiat, efek samping dan kontra indikasi. Kegiatan ketiga; setiap peserta diminta untuk melakukan pencarian data langsung di masyarakat agar dapat meningkatkan pengetahuan tentang swamedikasi. Setelah pemberian penjelasan tentang 3 kegiatan diatas, penyuluhan ditutup dengan penjelasan berupa rangkuman oleh narasumber mengenai manfaat pengetahuan tentang pemilihan dan penggunaan obat yang tepat, baik dan benar serta memberikan pesan-pesan untuk memperkuat dampak intervensi.

\section{Evaluasi}

Evaluasi pada kegiatan Pengabdian Masyarakat ini melalui pendampingan dan test (pretest-posttest). Evaluasi ini bertujuan untuk mengetahui apakah ada kendala, kelemahan dan kekurangan selama proses pelaksanaan transfer ilmu pengetahuan di sekolah. Setelah program pengmas ini selesai diharapkan siswa-siswi SMPN 15 Kendari dapat mengedukasi keluarga serta diri sendiri dalam mengelola obat secara swamedikasi dan bijak dalam penggunaannya.

\section{HASIL DAN PEMBAHASAN}

Kegiatan sosialisasi yang telah dilaksanakan pada SMPN 15 Kendari merupakan salah satu rangkaian program Kementrian Kesehatan yang dilaksanakan oleh Dinas Kesehatan IAI dan Ikatan Apoteker Indonesia Kendari. Dalam pelaksanaannya disesuaikan dengan Surat Keputusan Menteri Kesehatan Nomor 427/2015 tentang Gerakan Masyarakat Cerdas Menggunakan Obat. Diharapkan dengan adanya kegiatan para pelajar SMPN 15 Kendari mampu menggunakan obat dengan baik dan bijak, memiliki kesadaran dalam memilih dan membeli obat serta mampu memberikan pengetahuan kepada masyarakat tentang efektivitas dan keamanan obat-obatan yang beredar di masyarakat baik obat bebas maupun obat bebas terbatas. Kegiatan ini diikuti oleh 25 orang siswa siswi SMPN 15 kendari yang terdiri dari 15 orang siswi (60\%) dan 5 orang siswa (30\%).

Kegiatan ini dibagi menjadi 3 tahap, yaitu pre test, intervensi dan post test menggunakan kuesioner. Tahap pretest, dilakukan dengan membagikan kuesioner pada peserta. Setelah dilakukan pengambilan data pada saat pretest responden akan diberikan sosialisasi tentang penggunaan obat secara baik dan benar melalui edukasi GEMA CERMAT dengan metode CBIA, yaitu berupa diskusi yang dilakukan dengan membagi 7 kelompok yang terdiri dari 3-4 orang dimana apoteker sebagai narasumber untuk mendampingi sekaligus memberikan pemahaman tentang penggunaan obat secara rasional. setelah dilakukannya diskusi, responden diminta kembali mengisi lembar kuesioner atau posttest.

Setelah dilakukan tahapan pretest, intervensi dan posttest maka diperoleh adanya pemahaman 
tentang penggunaan obat secara rasional dilihat pada Tabel 1 di bawah ini:

Tabel 1. Evaluasi Pemahaman Penggunaan Obat Secara Rasional

\begin{tabular}{lcc}
\hline Parameter & $\begin{array}{c}\text { Rata-Rata Nilai } \\
\text { Pretest }\end{array}$ & $\begin{array}{c}\text { Rata-Rata Nilai } \\
\text { Posttest }\end{array}$ \\
\hline Obat-obatan & 60 & 100 \\
Jenis/Bentuk Obat & 50 & 100 \\
Penggunaan obat & 50 & 100 \\
Penyimpanan obat & 45 & 100 \\
Pembuangan obat & 30 & 100 \\
\hline
\end{tabular}

Berdasarkan tahapan test (Pre-Post) dapat dilihat bahwa dengan adanya penyuluhan dan intervensi yang diberikan oleh Apoteker dapat meningkatkan pengetahuan pada siswa-siswi SMPN 15 Kendari dalam memilih jenis dan bentuk obat yang tepat, menggunakan obatobatan dengan baik dan bijak, mengetahui cara menyimpan obat dengan benar serta cara membuang obat-obat yang benar dan tepat sehingga program pemerintah pencanangannya melalui SK Menkes No. 427/2015 tentang Gerakan Masyarakat Cerdas Menggunakan Obat dapat terlaksana dengan baik dan tepat sasaran.

Pelaksanaan intervensi disajikan dalam bentuk pemaparan singkat dengan menggunakan media pembelajaran yang lebih menarik, nyata dan langsung kepada pelajar (Gambar 1). Setiap peserta dalam kelompok akan melakukan pengamatan pada kemasan obat yang mencantumkan senyawa yang terkandung didalam obat tersebut. Kemudian setiap peserta mengamati tulisan sehingga mampu untuk menyebutkan bahan obat apa saja yang tertulis dalam kemasan obat tersebut. Selain itu, peserta juga harus bisa menemukan informasi penting lainnya seperti indikasi, efek samping, interaksi, kontra indikasi, aturan pakai, tanggal kadaluarsa dan penggolongan obat. Hasil dari diskusi pengelompokkan obat tersebut dicatat dalam lembar kerja yang disediakan. Apoteker akan menganalisa dan mendiskusikannya dengan peserta, dimana peserta (pelajar/siswa) dapat saling berdiskusi membahas permasalahan apa yang ditemui saat melakukan pengamatan dan mengajukan pertanyaan untuk dibahas bersama. Hal ini dilakukan agar peserta (pelajar/siswa) memperoleh informasi yang dapat dijadikan acuan dalam melakukan pengobatan sendiri sesuai dengan pedoman rasionalitas obat.

Diharapkan dengan adanya progam Gema Cermat ini akan memberikan manfaat yang besar bagi peserta yaitu untuk adanya peningkatan pemahaman dan kesadaran pelajar tentang pentingnya menggunakan obat dengan benar, meningkatkan kemandirian dan perubahan perilaku dalam memilih dan menggunakan obat secara benar, dan akhirnya akan meningkatkan penggunaan obat secara rasional, kegiatan progam Gema Cermat ini dibuat agar tidak menjenuhkan, maka diisi dengan diskusi terbuka mandiri antara peserta dan apoteker agar para peserta (pelajar/ siswa) mampu menyerap ilmu yang diberikan dengan cepat, serta adanya transfer ilmu dan pengetahuan cara peserta melakukan pemilihan obat bebas dan obat bebas terbatas yang beredar di pasaran yang menunjukkan adanya dampak positif dari intevensi yang dalam hal edukasi tentang swamedikasi obat di apotik atau toko obat.

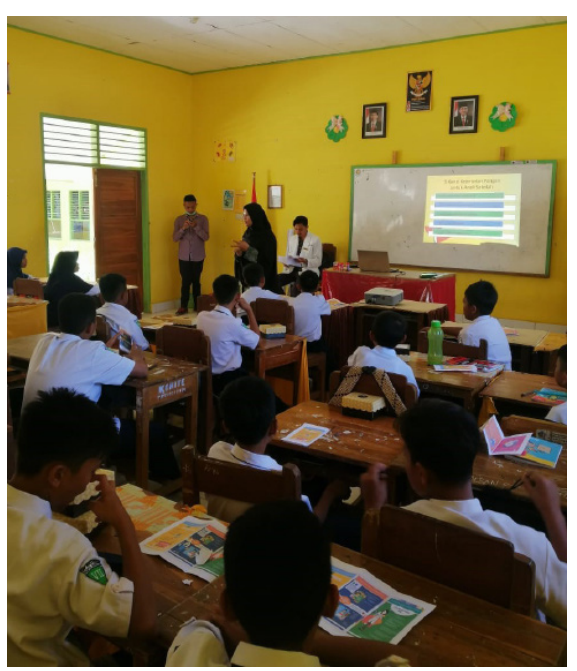

Gambar 1. Penyuluhan dan Pembinaan di SMPN 15 Kendari

Pada akhir kegiatan dilakukan pemberian hadiah pada adik- adik pelajar yang aktif pada sosialisasi GeMa CerMat untuk menambah semangat mereka dalam mengikuti kegiatan ini. Para siswa sangat senang dan gembira atas terlaksanannya kegiatan ini dilihat dari seberapa sering mereka mengajukan pertanyaan tentang masalah penggunaan obat (Gambar 2).

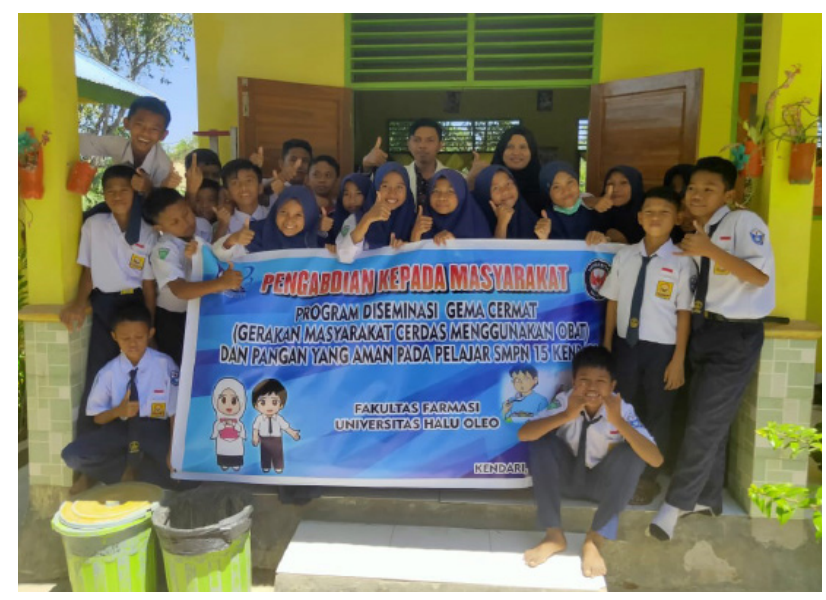

Gambar 2. Foto Bersama Siswa-Siwa SMPN 15 Kendari pada Penyuluhan dan Pembinaan GeMa CerMat 


\section{KESIMPULAN}

Program Gerakan Masyarakat cerdas menggunakan Obat dapat meningkatkan pemahaman siswa SMPN 15 Kendari dalam hal pengelolaan dan penggunaan obat dengan baik dan bijak sesuai dengan pedoman rasionalitas pengobatan. Penggunaan obat yang rasional dan pengobatan sendiri atau swamedikasi, sehingga diharapkan dengan adanya progam gema cermat peserta (pelajar/siswa) dapat meyalurkan dan melakukan semua sesuai informasi yang telah diperoleh agar tidak terjadi penyalahgunaan obat di masa yang akan datang.

\section{UCAPAN TERIMA KASIH}

Terima kasih yang sebesar-besarnya kami ucapkan kepada pihak-pihak yang telah membantu selama kegiatan pengabdian masyarakat. Adanya bantuan dari semua pihak, akhirnya pelaksanaan kegiatan pengmas ini bisa berjalan dengan baik. Penulis menyatakan tidak ada konflik kepentingan dengan pihak-pihak yang terkait dalam kegiatan pengabdian kepada masyarakat ini.

\section{DAFTAR PUSTAKA}

Bela, A., Suryawati, S., Rustamaji. 2016. Intervensi CBIA untuk Meningkatkan Pengetahuan, Sikap, dan Perilaku Penggunaan Antibiotik yang Rasional pada Anggota Bina Keluarga Balita CBIA. Jurnal Kedokteran Brawijaya Vol. 29(2). Pp. 165-169.
Ihsan, S., Sabarudin, S., Leorita, M., Syukriadi, A. S. Z., Ibrahim, M. H. 2017. Evaluasi Rasionalitas Penggunaan Obat Ditinjau dari Indikator Peresepan Menurut World Health Organization (WHO) di Seluruh Puskesmas Kota Kendari Tahun 2016. Medula Vol. 5(1). Pp. 402-409.

Kementerian Kesehatan Republik Indonesia. 2015. Keputusan Menteri Kesehatan Nomor 427 Tahun 2015 tentang Gerakan Masyarakat Cerdas Menggunakan Obat. Jakarta: Sekretariat Negara.

Lathifah, M.A., Ilham, M., Wibowo, A. 2015. Perbandingan Metode CBIA dan FGD dalam Peningkatan Pengetahuan dan Ketepatan Caregiver dalam Upaya Swamedikasi Demam pada Anak Abstrak. Pharm Sci Res Vol. 2(2). Pp. 89-100.

Nining, Y. 2019. Edukasi dan Sosialisasi Gerakan masyarakat Cerdas Menggunakan Obat (Gema Cermat). Jurnal Pengabdian kepada Masyarakat. Vol. 5(1). Pp. 36-48.

Rachmawati, S. 2016. Upaya Peningkatan Pengetahuan Pada Pelajar SMAN 1 Bantul tentang Pencegahan Penyalahgunaan Narkoba dengan Intervensi CBIA-Narkoba. Jurnal IKESMA Vol. 12(1). Pp. 1-7. 